Dr Meg Jensen, Director

Life Narrative Research Group,

Kingston University

Penrhyn Road, Kingston Upon Thames

Surrey, KT1 2EE

United Kingdom

02084172282

m.jensen@kingston.ac.uk 
Surviving the Wreck: Post-traumatic Writers, Bodies in Transition and the point of Autobiographical Fiction

This is an Accepted Manuscript of an article published by Taylor \& Francis in Life Writing on 16 February 2016, available online:

http:/ / www.tandfonline.com/ 10.1080/ 14484528.2016.1141034 . 


\section{Abstract \\ Surviving the Wreck: Post-traumatic Writers, Bodies in Transition and the point of Autobiographical Fiction}

In autobiographical fiction, the repetition of specific 'unprocessed' tropes wherein contextual meaning remains unclear can be likened to the symptomatic 'flashbacks' endured by victims of trauma. Virginia Woolf's compulsive use of images of sea, mirrors, and unspoken shame, Jack Kerouac's brothers and angels, J G Ballard's empty swimming pools, Melville's tropes of Narcissus and madness and my own return to images of blood and wounding in my work, are part of each writer's attempt to construct a new post-trauma narrative identity. Writing fiction enabled these writers to shake off the fixed subject position dictated by their pasts and construct new and more multifaceted identity narratives as survivor-writers. As Maggie Schauer's work demonstrates, through narrativization a new 'sense of perceived identity may emerge: 'who I am now' and 'who I was' when trauma struck. These narratives comprise the past as a story written post-traumatically, and a new identity (as a survivor/writer) they have narrated for themselves. Autobiographical fiction, therefore, may be central to understanding the function of self-narrative in the construction of post-trauma identities. This essay considers what such texts can tell us about trauma and the body, trauma narratives and autobiographical fictions, and writing and post-traumatic identity.

\section{Keywords:}

Trauma; Narrative; Autobiography; Identity 
'He did not feel the wind, or smell the salt air. He only stood, staring at the horizon, with the marks of some inner crucifixion and woe deep in his face. 'Melville, Moby Dick

\section{1. "that story of Narcissus"}

Herman Melville was the author of numerous novels and short stories, but his entire oeuvre might best be understood as a response to the question that arises at the start of his most famous work, Moby Dick.

Why did the old Persians hold the sea holy? Why did the Greeks give it a separate deity, and own brother of J ove? Surely all this is not without meaning. And still deeper the meaning of that story of Narcissus, who because he could not grasp the tormenting, mild image he saw in the fountain, plunged into it and was drowned. But that same image, we ourselves see in all rivers and oceans. It is the image of the ungraspable phantom of life; and this is the key to it all. (3)

As any biographer of Melville will tell you, Melville's childhood was marred by his father's bankruptcy, emotional instability and early death, and his later life was blighted by his belief that he had inherited his father's madness. ${ }^{1}$ Melville's work contains an overwhelming number of images of inconsolable suffering and madness brought on by sudden, traumatic loss. As I have argued elsewhere, the repetition of specific 'unprocessed' tropes whose contextual meaning remains unclear can be likened to the symptomatic 'flashbacks' endured by victims of trauma (J ensen, 2012). Such images appear repeatedly in the works of many writers who suffered much in childhood. This essay considers what these textual representations suggest about trauma and the body, trauma narratives and autobiographical fictions, and writing and post-traumatic identity.

\footnotetext{
${ }^{1}$ The ongoing effect of Melville's childhood difficulties on his psychological state and his writing life are explored in all recent biographies. See for example Delbanco, 2005, Parker, 2005 and Rogin, 2012.The psychotherapist Edwin Shneidman reads several passages in Redburn as evidence of Melville's suicidal thoughts. See Shneidman, 2004, p. 161.
} 
Throughout Melville's work from 'Bartelby' to Billy Budd, arises the question of difference inscribed by a post-traumatic state: the altered relationship to meaning and body, and therefore to the experience of life itself, which trauma victims endure. The following passage from Redburn, for example, represents the fatherless hero's loss as both psychologically dissociative and physically painful: 'I must not think of those delightful days, before my father became a bankrupt . . . [or] something rises up in my throat and almost strangles me. . ' (WHM 4:10) The agony Melville illustrates here, moreover, is terminal: 'never again can such blights be made good [...] they strike in too deep and leave such a scar that the air of paradise might not erase them' (WHM $4: 11$ ) This reflection, written in the 1840s, might be taken as a prescient definition for the condition we now refer to as Post-Traumatic Stress Disorder (PTSD).

In 1980, the term PTSD entered into modern psychology in the third edition of the Diagnostic and Statistical Manual, of the American Psychiatric Association (DSM-III, APA), a book used by clinicians and researchers to diagnose mental disorders. The most recent edition of the manual, DSM-V (2013), contains an entire chapter devoted to traumatic related disorders. This addition reflects advances in knowledge and understanding of PTSD and the variety of ways it might present. According to DSM-V, the trigger for developing PTSD and related disorders is exposure to actual or threatened death, serious injury or sexual violation. PTSD can arise from directly experiencing or witnessing the traumatic event, learning that a traumatic event occurred to a close family member or friend, or by experiencing first-hand repeated or extreme exposure to upsetting details of the traumatic event.

DSM-V goes on to propose four distinct clusters of symptoms: re-experiencing (disturbing and spontaneous flashbacks or nightmares), avoidance (of persons or situations that may trigger memories of the experience), negative cognitions (such as depression, estrangement, self-blame or memory difficulties) and arousal (aggressive behaviour, hypervigiliance, sleep disturbances, etc.) 
It is worth noting here that not everyone who witnesses a traumatic event will develop PTSD, and that there is no clear agreement among mental health practitioners about the precise causes and mechanisms of the disorder. Recent research has suggested that some people may be more likely to become traumatised than others, whether through a genetic predisposition or because of their early-life experiences. More work is being done in this area to see if it is possible to 'predict' and possibly prevent traumatic disorders in some way. ${ }^{2}$ One compelling interpretation of the disorder is offered by clinical psychologist Robert Strickgold. He explains that the defining characteristic of PTSD is 'failed memory processing, characterized in part by the [...] inappropriate dominance of specific episodic memories of traumatic events' (Strickgold, 61-75). These events, Strickgold explains, are trapped as unprocessed sensory perception (64), and because they are stuck in one time and place, they can reemerge at any time with a sensory power that, in Melville words 'almost strangles me.'

Psychoanalyst J uliet Mitchell's offers another, somewhat controversial, account of trauma. Mitchell has argued that because of the difference in the way traumatic memories are processed, PTSD has a specific relationship to language and meaning. She writes,

the trauma sufferer withdraws from reality at the level of her or his own language. But then something reendows this language with energy [...] That which is spoken is the language of a mimed consensus or a compulsive repetition [...]. Since there is not meaning to this language, the notorious lying of the hysteric fits in here. (130)

Mitchell's use of the term 'hysteric' here hints at an approach to trauma that contemporary mental health practitioners would no doubt find dated (Mitchell is writing

\footnotetext{
${ }^{2}$ Following suit, the treatment literature regarding PTSD has changed drastically from the previous focus on more traditional cognitive and exposure therapies to the point to where even genetic testing to determine the appropriate psychopharmacological intervention has been recommended (Bowirrat, et al., 2010).
} 
here in 1998). The most common form of treatment for traumatic disorders today is Cognitive Behavioural Therapy (CBT). CBT is based on the idea that our thinking and beliefs impact directly on how we feel and aims to restructure negative, unhelpful thoughts into positive, helpful ones. What Mitchell proposes here, however, is not a mode of trauma treatment but a useful analysis of traumatogenic text. I can't help but wonder whether the 'withdrawal from reality' at the level of 'language' Mitchell points to might account for the recourse to fiction that is taken by many post-traumatic writers. Trauma forges in its victims, Mitchell argues, a vital relationship to language, endowed with 'energy,' but coded and repetitive: it is 'a verbal version of the visual language of dreams: words are metaphors, similes and symbolic equations,' 'expressions of feeling rather than of meaning' (132).

In the quotation from Moby Dick above, Melville points to the relationship between the pull of autobiographical feeling on the one hand and an awareness of the 'ungraspable phantom of life' on the other. 'Surely all this is not without meaning,' he writes, but that meaning is only available to the fictive autobiographer I shmael through the medium of allegory. The story of Narcissus is the story of ourselves, drowning in our own reflections. But this tale is more than meta-narrative for Ishmael. Narcissus inscribes meaning onto Melville's own experience: the act of narration itself allows the ungraspable phantom a context in which it can be both written and read (if not captured) and this is, as our narrator tells us, is the 'key to it all.' The connections Melville drew in his fiction between story-telling, a different, disembodied self and the universal desire to identify meaning in experience, have not only been echoed in the works of many other post-traumatic writers but also in contemporary theories of the relationship between narrative and identity. ${ }^{3}$ In the last five years, moreover, these same links have been drawn upon in the development of evidence-based narrative therapies for trauma. ${ }^{4}$

\footnotetext{
${ }^{3}$ See for example Gilmore, 2001, and J ensen, 2014.

${ }^{4}$ Robjant and Fazel, 2010, p. 1030
} 


\section{2. 'I would prefer not to' ('Bartelby the Scrivener')}

Recently I have developed a project with a colleague for the UK Foreign and Commonwealth Office (FCO) that will make use of the latest research on narrativebased therapy to adapt life writing exercises for victims of sexual violence in conflict. Before doing so I read through the FCO's recently published International Protocol on the documentation of such crimes. The overriding ethos of the Protoco/ is the directive to 'do no harm' to victims in the process of investigation (29). In the section on interviewing and collecting testimony, the Protocolsuggests that the interviewer should "Make sure to cover the "who", "what", "where", "when" and "how" of the crimes (while remaining wary about asking the survivor/witness any "why" questions, so as not to apportion blame to the survivor/witness' (114). While the pursuit of a linear, chronological collection of data outlined here might suit legal purposes, research in trauma studies has long demonstrated that traumatic experience disrupts normal memory processes, leaving victims with a fractured sense of their past. Indeed, Paul J ohn Eakin has argued that such narrative incoherence is itself an emblematic symptom of poor mental health (Eakin, 2008).

This post-traumatic disruption of linear life narratives means that the Protocol's suggested interview approach is neither practical in terms of the collection of data, nor beneficial to victims. By using such methodologies interviewers may unknowingly be 'doing harm,' as they pushed victims to recall terrifying experiences in a manner that is either re-traumatising or simply impossible. Moreover, while the Protocol advises interviewers to avoid any considerations of 'why,' victims of trauma cannot begin to heal until they are able to construct some narrative of 'meaning' for their experiences. ${ }^{5}$ I have to confess, however, that I thought of none of these things when I first read the interview guidelines in the Protocol. Instead, when I saw the list of questions 'who',

\footnotetext{
${ }^{5}$ For further reading on this finding, see Robjant and Fazel, 1031; Nicholls, 2009, p. 173-4 and MacPherson,2012, p. 30.
} 
'what', 'where', 'when' and 'how,' I felt very much like Melville's fatherless child: something rose in my throat and strangled me.

\section{You must have plenty of sea-room to tell the truth in' ('Hawthome and his Mosses')}

Let me tell you a story. When I was ten years old, two very bad things happened to me. One was easily named. One was not. The result the first of these events was a terrible sense of loss which lessened over time. The result of the second was post-traumatic stress disorder, diagnosed in adulthood, and with which I continue to struggle in middle age. In a number of therapeutic settings over the years, I have been told the reasons my differing reaction to these two events. That which I was able to name could be understood, processed and accepted. But that of which I could not speak continued to haunt me. I took my therapists at their word and spoke. I tried to tell the story of what happened to me, over and over and over again. For reasons I have only just begun to understand, I found it nearly impossible to do what was asked of me. The who, what, when and where eluded me. What mattered to me was the question that could not be answered. The 'why.' Moreover, as the therapists made clear, unless I could tell my past, there was little hope of healing in my future. And so I suffered. And I wrote. I wrote fiction based on autobiographical material. I invented a character just like me (called Bernadette) who had many of the same experiences I had and then imagined what would happen to her in the future. I had to write my story as fiction rather than fact because as my therapy had shown, my grasp of the facts was unreliable at best. And anyway, in fiction I could create my own answer to the unanswerable question.

As Maggie Schauer, the leading figure in the development of narrative based treatments for trauma, has noted 'it might seem that narration and trauma are radically opposed and mutually exclusive, as the people suffering these crimes are in too much pain [...] to share their stories. However, these cannot remain buried forever, and eventually the victim will be compelled to speak (Schauer et al, 12).' 
Here is an excerpt from the novel that arose from just such a compulsion.

From Meg J ensen, Saints on Staten I sland 2011

Bernadette's Creative Writing Notebook

Date:October 221999

Title:Time Line

Bernadette was attacked when she was nine or ten years old. She can't remember the exact date. That is, she can't remember if it happened before Andrew died or after-which probably means it was after-in the time when nothing much worth remembering in any linear way happened. Bernadette remembers this period in an audible, aural way instead. She remembers sounds, words especially, words that were spoken and words that were choked, and who said them to whom. But when, and in what order, or with what consequences [...]-it doesn't come back to Bernadette that way.

This lack of chronological sequencing doesn't bother Bernadette-it didn't really matter in which order the plagues descended did it? Was it locusts first or floods? It is enough to know that they came. That the horrors did not desist. That some died and others lived to write about it. Her shrink didn't see it that way, of course. Resistance, defense mechanismsthese were the words that hung about the analyst's office. "But why were you there, Bea? In the park? " Why indeed.

Bernadette could not follow. She did not want to remember, to place events in a continuum, to see their cause and effect. "Bernadette's time-line" was the project her shrink wanted to her to complete. So she did. On a big piece of white poster board, using black stenciled letters and a large, red line to connect the dots. She'd made most of it up. $(2011,165)$

Although Saints in Staten Island is a work of fiction, this passage is based on something I did in real life. What I did not understand back when I delivered the poster-sized half made-up time-line to my psychiatrist was that for many post-trauma sufferers like me, 
the linear codes and conventions necessary to producing life narratives are unrecoverable and/or inaccessible: factual, chronologically arranged narratives and trauma are at cross-purposes. As Schauer notes it is extremely difficult for [patients] to narrate the event in a detailed consistent and chronological manner [...] they can remember the event all too well, as they suffer from painful involuntary recollections. However, if asked to report the event the narrations are typically disorganized, fragmented, and incoherent' (Schauer et al, 21). ${ }^{6}$ So how are we to get better?

For most persons, self-narratives or 'life stories' provide space for the reflection upon and the processing of experience. As Sophie Nicholls has argued, much of the current research on the therapeutic potential of creative writing for trauma survivors 'employs the notion of a "holding space," a space in which we can feel both sufficiently free and sufficiently sage to let go and begin to access increasingly felt, bodily material [...]. Current findings suggest that the page itself can provide some of this holding (174). ${ }^{7}$

Recently I went back to therapy. It turns out that while I still suffer from many symptoms of PTSD, there are some which no longer trouble me: vivid flashbacks, for a start. Although I regularly have nightmares, the images that chase me are vague and changing-not specific and recurring as they once were. My new therapist wondered why. And he asked me to tell him my story. But this time instead of recounting it all again, I gave him my novel to read. And here is what he and I came to understand. Although writing the novel did not heal me, by providing a 'holding space' of the kind Nicholls suggests-writing helpedme. It seems that by reflecting upon my experiences and integrating them into a story with a beginning middle and end, I have to some extent placed those events in the past. My anxieties are there still in the dark places of

\footnotetext{
${ }^{6}$ Here, Schauer draws on Bessel van der Kolk's study of memory fragmentation in trauma. See Van der Kolk, 1995.

${ }^{7}$ Here Nicholls draws on both Dale Winnicot's notion of 'a holding space' (Winnicott, 1971) and McLoughlin's study of poetry in hospice care (McLoughlin, 2000).
} 
my soul, but they spend more time these days waiting and watching than pounding at the door. What writing the novel did was give me a new story to tell-a new identity: Bernadette, my character, was the victim of tragedy. I, Meg J ensen, am a writer/survivor, in charge of the narrative of my life. Moreover, this process of narrating, reflecting and moving experience into the past is, I know now, vital for all victims of trauma.

\section{4. "And never again can such blights be made good," ( Redburn)}

In 1999 psychologist J ames Pennebaker and his colleagues initiated studies to investigate the empirical bases (if any) for the therapeutic effects of writing. These studies clearly demonstrated the benefits of 'writing therapy' for both physical and mental health (Pennebaker and Seagall,1999). Nevertheless, Pennebaker and his colleagues later concluded that 'despite the beneficial effects of writing, it is not entirely clear why it is effective in bringing about such striking physical health and behavior change' (Esterling et al, 85). In the period since, Celia Hunt has done much work on what she terms Transformative Learning through Creative Life Writing. Hunt argues that fictive forms of life story-telling may increase the writer's 'awareness of spontaneous bodily feelings and emotions, and a more reflexive relationship between different aspects of themselves' (2010, 232). These ideas have developed, she explains 'in light of the new thinking about self and consciousness in the cognitive and neurosciences, where the self is being understood as first and foremost an innate, bodily-felt process and only secondarily as a product of language' (2013, xiii).

Hunt makes use of neurophysiologist Antonio Damasio's two-part model of the unconscious self-an early pre-lingual, non-reflexive 'core self' that arises from bodily perceptions, and an 'autobiographical self' that is imposed by and through the acquisition of language (Damasio, 2000). In a healthy person these two selves are 'in process rather than fixed entities,' with reflexive fluid movement between them. 
Traumatic experience, however, can limit access to this bodily felt self, with the result that, 'we may experience blocks to or stiffness in, cognitive processing' (Hunt, 2010, 232). And that is where, Hunt claims, 'writing that uses fictional and poetic techniques to capture self-experience' can be of help (2010, 232). Writing fictional autobiographical narratives, Hunt argues, enables healing, as it 'involves learning to trust the aesthetic of the writing process rooted in the felt body' $(2010,240)$. The 'deictic shift' in such work transforms problematic frames of reference, easing 'psychic stuckness through facilitating the [...] development of a stronger and more flexible sense of self rooted in the felt body' $(2010,240)$. This new self is re-embodied as the writer allows 'hidden or unknown aspects of the self' to be indirectly revealed through the use of metaphor and form. The work of creative life writing in such cases, Hunt suggests, provides 'a closer engagement with the body's felt perceptions and emotions' (2010, 234-5).

In the last two decades, much work has been done by literary critics exploring structural and epistemological relations between the traumatic events of some writers' lives and the figurative forms they have used to articulate their experiences. In works such as Suzette Henke's Shattered Subjects (1998) Leigh Gilmore's The Limits of Autobiography (2001) and Anne Whitehead's Trauma Fiction (2004) the relationship between form and feeling is most usefully examined, problematized and interrogated. Reflecting upon this important work in light of Hunt's reading of the transformative relation between creative writing and the body, led me to consider the new identity narratives that are being forged in post-traumatic autobiographical fictions. Writers of such works, I suggest, use fictive forms not only to confront and rewrite the incidents that inscribed their sense of difference-but to also, in effect, rewrite themselves.

\section{5. 'I only am escaped... alone, to tell thee.' (Moby Dick)}

Throughout the twentieth century therapists from a variety of backgrounds and clinical approaches increasingly came to believe that the ability to name our sufferings was integral to the process of recovery. Indeed, since the 1980s narrative therapy has 
become a mainstream therapeutic modality. ${ }^{8}$ Thus, whether a victim seeks familial acceptance or legal justice, a form of words must be found to name their trauma in order to narrate a new identity that locates it in the past. But, while public justice cannot be served unless an atrocity is narrated, the form of narration that is useful to victims is likely to be very different that which is useful to the state.

In Theodor Adorno's attack on the notion of cultural criticism, he famously argued that 'to write poetry after Auschwitz is barbaric' (34). Leigh Gilmore echoes this idea in The Limits of Autobiography, when she explains that 'to take one view, trauma cannot be spoken of or written about in any mode other than literal. To do so risks negating it' (7). This idea that only fact-based accounts of trauma are of value is linked to the need for historical accuracy in public records of atrocity in its aftermath. Such thinking nevertheless flies in the face of what many victims of trauma find helpful. Like many other survivors of violent childhood trauma, the retelling of the 'vital statistics' of my past on the analyst's couch served only to re-traumatize me. What helped was writing autobiographically based fiction. As Gilmore explains:

Because testimonial projects require subjects to confess, to bear witness, to make public [. . . ] they enter into a legalistic frame in which their efforts can move quickly beyond their interpretation and control [. . . ] some writers move away from recognizably autobiographical forms, even as they engage autobiography's central questions. (7)

As Gilmore suggests here, metaphoric and mimetic modes of narrating trauma have historically been seen as negating, distorting or, as Adorno argued, even insulting the truth of actual events. Nevertheless, these forms may better serve the needs of the survivor/writer who is not searching for the facts of the past but for a way to live in the future. For cases in which a retelling of factual details might 'do harm,' metaphoric and representational modes of narration serve a number of essential purposes, not least of which is the establishment of a new, non-victimized self-hood.

\footnotetext{
${ }^{8}$ For an overview, see Payne, 2006 and the following website: http://www. narrativetherapycentre.com/index files/Page378.htm
} 
Despite some significant recent challenges, psychoanalysts since Freud have generally agreed upon the centrality of narratives of identity, however fluid or fragmented, to our experience of selfhood. ${ }^{9}$ Martin Payne, in his excellent overview of narrative therapeutic approaches highlights the 'common ground' between what are now called 'narrative therapies' and more traditional psychoanalysis, stating that 'the concept of "narrative" does provide a place where therapeutic minds can meet' (8) Eakin, as noted earlier, has argued that in effect narrative is identity. He explains this idea by retelling the story of William Thompson, a patient of the late neurologist Oliver Sacks. Mr. Thompson lacked short term memory, and therefore a coherent life story, yet he was psychologically compelled to construct new narrative identities day in and day out. He needed a life story in order to exist to himself (Sacks, 1985). Victims of trauma, I suggest, are likewise compelled to construct new self-narratives because their relationship to a particular set of past perceptions is mediated by difference: traumatic experiences that have remained trapped in their short term memories, unnarrativised, unprocessed, and therefore never understood.

As we have seen, however, those suffering post-traumatic disorders experience difficulties in remembering, and that in such contexts the 'truth' and 'historical accuracy' of these self-narratives are fraught concepts. Thus, while Philippe Lejeune's autobiographical pact proclaims that the author, narrator and protagonist must be the same and have the same 'vital statistics', post-trauma autobiographers have trouble accessing and navigating such statistics (21). Celia Hunt developed this idea in her own study of the Therapeutic Dimensions of Autobiography (2000). There, Hunt argued that autobiographers can gain therapeutic benefits if they employ techniques of mimetic fiction to create a narrator out of the self. She also suggests, however, that such 'fictionalising of ourselves can only have value' if we 'try to be as honest as possible'

\footnotetext{
${ }^{9}$ Galen Strawson among others has dismissed the primacy of narrative identity and argues instead for two possible cognitive states which he calls the 'Episodic' and the 'Diachronic.' See Strawson, 2004. See also an overview of challenges to narrative identity in Eakin, 2008, pp. 8-17.
} 
(162-3). Citing Lejeune, Hunt goes on to state that the 'autobiographical pact with ourselves will provide us with a framework of honesty and truth-seeking within which we could pursue our personal truth through the imagination' (163). In Hunt's account, that is, imagination combined with a desire to pursue 'personal truth' through the use of fictional techniques, provides writers with clear therapeutic benefits.

\section{The drama's done. Why then here does any one step forth? - Because one did survive the wreck'. (Moby Dick)}

In Visions of Gerard, the autobiographical novel that recounts his brother's life and early death, J ack Kerouac writes of his reason for becoming a writer:

I've since dreamed it a million times [...] the house on Beaulieu Street the night Gerard died [...] I don't see him in the coffin but he's there, his ghost, brown ghost, and I'm grown sick in my papers (my writing papers, my bloody 'literary career' ladies and gentlemen) and the whole reason why I ever wrote at all [...] because of Gerard. $(1963,10)$

For Kerouac, as he describes here, the trauma of witnessing his brother's painful early death is central to the construction of his own adult narrative identity-an identity that both links Kerouac to the past and detaches him from it. Kerouac trauma blighted him throughout his life, he tells us, but his compulsion to tell and retell the story of his loss transformed him into much more than the victim of that experience: in his brief life Kerouac became a ground-breaking, best-selling author as well as pioneer and figurehead of the American counter-culture movement (Tytell, 1976).

As Eakin notes, Oliver Sacks's work raises the question 'What is a man without his story?' Maureen Whitebrook, whose own research is in the area of political identity, likewise argues that by and large 'persons understand their own lives as stories,' and that for most of us, such stories are complex, multivalent and open to interpretation by both speaker and listener:

Narrative identity [ . . . ] consists of stories we tell to ourselves about ourselves and the stories we or others tell to others, or stories that are told 
to others about ourselves-all the stories in which we are included [. . . ] Narrative identity [...] entails answerability and responsibility and the capacity for negotiation. (10)

Historian Dominick LaCapra, on the other hand, argues that this open-ended form of self-hood is not possible for victims of trauma who instead become trapped in a limited 'total' identity narrative. This fixed subject position is, he claims,

a partial, problematic identity [...], a subject position becomes a total identity only in cases of extreme 'acting out' wherein one is possessed by the past and tends to repeat compulsively as if it were fully present [...] and a victim's recovery may itself depend on the attempt to reconstruct the self as more than a victim (12).

J ust as Whitebrook pinpointed a 'capacity for negotiation' as necessary to the creation of healthy, open and complex self-narratives, LaCapra identifies a 'reconstruction of the self' as the key to post-traumatic recovery. Such narrative negotiation, I would argue, is at the heart of what post-traumatic seek when they compose autobiographical fiction. For while factual self-narratives may impose the fixed role of victim, fictive forms allow that subject position to be continually re-negotiated. As established in the work of Henke, Gilmore, Caruth and others, the key stylistic features of autobiographically based post-trauma fiction (intertextuality, repetition, dispersed or fragmented narrative voice) manifest precisely this complexity while also enacting the resistance to linearity necessitated by traumatized cognitive processes. ${ }^{10}$

Eakin, Sacks and Whitebrook suggest, however, that all persons need life stories in order to form narrative identities, and they need narrative identities however contradictory or incomplete they may be, in order to survive. Kerouac's post-trauma narrative identity is enacted across the fourteen novels that comprise the Duluoz Legend, his serialized fictional autobiography. Much of this work is haunted by what

${ }^{10}$ See Caruth, 1995; Henke, 1998; Gilmore 2001. 
Kerouac called the 'brown ghost' of his brother. As Kerouac scholars will tell you, Jack wrote obsessively from childhood, compelled, like Sacks's patient, to continually construct new narratives. ${ }^{11}$ While he availed himself of numerous fictional identitieseach novel nevertheless tells a similar tale of unrecoverable loss, of brothers real or symbolic, forced apart by tragedy and misunderstanding. These works, therefore, mine the dark vein of his traumatic loss, repeating the fixed subject position of narrator/victim. J ack Kerouac, survivor/writer, however, was not an created through his fictional characters. Instead, I would argue that the agency of writing itself forged his new narrative identity: Kerouac the prolific author whose fourteen autobiographical novels articulated the dark events of his life though an original voice and spontaneous methodology that inspired generations of writers.

Evidence for this argument is contained in the prolixity of Kerouac and many writers of post-traumatic fiction. For them (or I should say, us) it appears, it is not the story that matters, but the dialogue with difference that occurs during the compulsive and ongoing construction of a new identity (as writer).

As Eakin states, we are conditioned to believe that:

our recognition as persons is to be transacted through the exchange of identity narratives [...] no satisfactory narrative (or no narrative at all) no self. (44)

In therapeutic terms, Eakin notes, the ability to deliver a coherent self-narrative is often accepted as a sign of (recovered) health and normality' (44n). In the case of trauma, where coherence, linearity and meaning are 'disrupted' by the ever-present 'now' of suffering, the victim will struggle to produce a sufficiently satisfactory narrative. And yet, as we have also seen, without such a coherent self-narrative, we are literally lost to ourselves and to others.

\footnotetext{
${ }^{11} \mathrm{~J}$ ohn Tytell has noted that after his brother's death, Kerouac, suddenly an only child, wrote stories as a 'systematic pursuit' recording daily the number of words. Tytell, 1976, p. 64.
} 


\section{To enjoy bodily warmth, some small part of you must be cold, for there is no quality in this world that is not what it is merely by contrast. Nothing exists in itself.' (Moby Dick)}

Discussions of epistemologies of narrative and self-narrative should not overlook the fact that aporia are at the heart of all forms of storytelling. As the philosopher Noel Caroll has argued:

Narratives make all sorts of presuppositions and it is the task of the reader, viewer or listener to fill these in. It is of the nature of narrative to be essentially incomplete [. . . ] the author relies upon what we know or believe about human psychology in order for narratives to be intelligible. (138-9) What Carroll argues on behalf of fictional narratives may be doubly useful in understanding the differences inherent in autobiographical stories that navigate the fragmentary spaces of memory, forgetting, public justice and longing in their construction. As Kate Douglas explains 'autobiographies are laden with memory loss, memory gaps, false memory and a plethora of other memory related controversy' (115). Such gaps and controversies are perhaps nowhere more prevalent than in the case of post-trauma autobiography.

The writer and theorist Roberta Culbertson confronts these difficulties when she contends that the aim of narrative-the linearization of experience-is in direct conflict with the constraints of post-traumatic existence, particularly for victims of violence. She argues that

No experience is more one's own than harm to one's own skin, but none is more locked within that skin [. . . ] Trapped there, the violation seems to continue in a reverberating present that belies the supposed linearity of time and the possibility of ending. [ . . .] It is not past, not 'memory' that is, [...] locatable in time at all. (179)

My own experience confirms Culbertson's claims. If victims of violent trauma are unable to ascribe a time-frame to their experiences, they may not be able to construct a viable 
self-narrative, and as Eakins suggests, the lack of such a self-narrative is read privately and publicly as evidence of illness.

Nevertheless, as Douglas has shown, some victims are able to write of their trauma in narrative form by making their bodies do the talking. Douglas, like Culbertson, draws attention to the connection between victims' narratives and the experiences 'locked within' their skin (Culbertson, 179). In many post-trauma autobiographies of childhood, Douglas points out, the 'traumatized body challenges the notion that trauma is unspeakable or unpresentable,' as graphic details of physical abuse are used to 'speak for' the traumatized author/victim. ${ }^{12}$

Culbertson's work offers a context for understanding this body-centered mode in autobiographies of violent trauma. She notes,

extremity and danger place the body in a circumstance that feels close to death, as if the body feared more [...] than the observing mind seeking to cope and place the body out of harm. [. . . The world appears a different place [...] with a decidedly metaphorical quality. (177)

The experience of violence, Culbertson argues, is best told through the body. Such telling is no simple thing, of course, as body language and narrative language are at odds. These difficulties for post-trauma narrativization are coupled with the symptomatic silence of sufferers, making fact-based trauma narratives that represent mind and body nearly impossible to construct (Robjant and Fazel, 1031). Victims have therefore often had to find other methods for telling their stories and creating those allimportant alternative identities. Thus, the use of symbolic, representational and metaphoric means to construct identity narratives expresses, as Celia Hunt's work predicts, the difference which trauma inscribes on the felt, bodily, self. And in such

\footnotetext{
${ }^{12}$ Such details, Douglas notes, are presented by authors for ostensibly therapeutic purposes, although the opportunity for ghoulish voyeurism may be what has propelled some of these texts to the bestseller list. See Douglas, 2010, pp. 150-169.
} 
texts we encounter the affected body in transition —at the cross roads with the lingual autobiographical self.

The importance of this transitional mode is made clear by Michael Richardson in his reading of Deleuze. Bodies of all kinds, Richardson argues,

reside on a spectrum between relative fixity and radical flux. [I]n the transition from one state or position to another, the body carries with it the potential of its becoming something new [...] the lines that connect what is now and what could become are affects. (155-6)

These 'affects' Richardson explains, are 'pre-cognitive and visceral experiences that shape and change bodies,' (156) and it is in their transition, this interface between body and language, past and present, that change itself is possible.

\section{To the last I grapple with thee; from hell's heart I stab at thee; for hate's sake I spit my last breath at thee.' (Moby Dick).}

In her work on the relation between trauma and memory, critic Cathy Caruth has argued that 'to be traumatized is precisely to be possessed by an image or event' (11). The neuroscience of trauma makes it clear that this possession is a literal, biochemical process-a failure of normal memory processing. ${ }^{13}$ It makes sense then that in their attempt to propel their traumatized minds and bodies out of this 'possession,' to 'transition from one state or position to another' and 'become something new,' victims of trauma may make repetitive use of traumatic images and events, or their metaphoric counterparts, within the new identity narratives. I have argued elsewhere that the repetitive use of key tropes and figures enact mourning in the works of post-traumatic writers, but as I examine my own writing and therapeutic experiences I see that these metaphoric moments do much more than that. ${ }^{14}$ Virginia Woolf's compulsive use of

\footnotetext{
${ }^{13}$ See Bottalico and Bruni, 2012, and Strickgold, 2002.

${ }^{14}$ See J ensen, 2012.
} 
tropes of sea, mirrors, and unspoken shame, J ack Kerouac's brothers and angels, JG Ballard's empty swimming pools, Melville's tropes of Narcissus and madness and my own return to images of blood and wounding, are part of each writer's vital process of creating a new post-trauma narrative identity. As Schauer's work demonstrates, through narrativization of traumatic experience a new 'sense of perceived identity may emerge: "who am I" at present and "who was I" when trauma struck me' (5). These narratives comprise the past as a story written by them, and the culturally acceptable future identity (as a survivor/writer) that they have narrated for themselves.

Traumatic experiences exacerbate the need to tell but also increase the tendency towards a flattened self-narratives, legible in only one, dark, context (Hunt, 2013, 58). In fiction, victims of trauma can reinvent, reimagine and rewrite experience, and throughout history writer/victims have done so. ${ }^{15}$ Woolf, Mansfield, J oyce, Rhys, Melville, Ballard, Dickens, Kerouac, Alcott-the list goes on and on-these writers drew upon the sense of difference to which their childhood experiences gave rise as fuel for their writerly imaginations. Writing fiction enabled them to shake off the fixed subject position dictated by their past and construct new and more multifaceted identity narratives. ${ }^{16}$ By doing so, we were no longer victims to be read publicly or privately in one context, but writer/survivors within polyvalent fields of personal, artistic and cultural reference.

\section{0.'Call me I shamel.' (Moby Dick)}

In 2006, JG Ballard reflected on his autobiographically-based novel Empire of the Sun, which explores his terrifying experiences as a child in a J apanese prisoner of war camp:

[M]y memories of the war concealed a deeper stratum of unease that I

preferred not to face. [ . . ] In fact, I found it difficult to begin the novel, until it

\footnotetext{
${ }^{15}$ See examples of trauma represented through fictive means in Gilmore, 2001; Caruth, 1995; Whitehead, 2004.

${ }^{16}$ Here I am drawing on Nicholls, 2009 (p. 174); Robjant and Fazel (pp. 1030-1031) and Hunt's concept of 'psychic stuckness' and its relief through 'transformative learning' enabled by creative life writing in Hunt, 2010, 232.
} 
occurred to me to drop my parents from the story [ . . . ] just as they had moved out of my life in Lunghua even though we were sharing the same room. [...] Once I separated J im from his parents the novel unrolled itself at my feet like a bullet-ridden carpet. In 1984 the novel was published, a caravel of memories raised from the deep. Enough of it was based on fact to convince me that what had seemed a dream-like pageant was a negotiated truth. (1) In this passage, Ballard identifies the delicate maneuvers he undertook in to tell the tale of his traumatic childhood: 'it occurred to me to drop my parents from the story.' Here, Ballard seems to echo the words of the philosopher Herbert Marcuse, who argues that the purpose of art is that it 'has the capacity to show that the world can be otherwise' (138). Marcuse's account fits with my own reading of imagination's role in the construction of post-trauma narrative identities. Simply put: autobiographical fiction allows the victim/writer a chance to inhabit (and indeed narrate) that other version of the world.

Whether that alternative narrative offers solace, suffering, empowerment or pain, its very production engenders the agency of the author. Whatever the repercussions of representing violence or suffering in the text, that is, the imagining and the telling emanate from the survivor/writer. And if Michael Richardson is right, then this transformation is not (or not only) semantic. The affective transition from what was to what will be involves 'pre-cognitive and visceral experiences that shape and change bodies' (Richardson, 156). In autobiographical fiction, I literally write a new self into being.

Ballard tells us that he gained an alternative version of the world through a process he calls a 'negotiated truth'. These elements of 'negotiation' and 'imagination' in the construction of life narratives, whether traumatic or otherwise, may remind us, worryingly, of the scandals over autobiographical hoaxes in recent times. Let me be clear then that what I am arguing for is not fiction 'passed off' fiction as non-fiction, 
however blurred the boundaries between these have become. ${ }^{17}$ Instead, I am asserting that fact-based autobiographical accounts of trauma may not be fit for a therapeutic purpose: recounting atrocity in linear narratives often fails to alleviate suffering, nor does it evoke lasting empathy in readers. As Kate Douglas has shown, 'resilient autobiographies are considered most appropriate, (and are the most commercially successful)' (158-9). Such resilience, Douglas notes, is presented in autobiographies of childhood trauma narrated by 'apparently self-actualized, successful' adults, now 'qualified to speak' on behalf of that childhood self. Particular kinds of performances, Douglas argues, are required of 'authors of traumatic autobiographies of childhood: resilience, recovery and self-reflexivity' (68). In post-traumatic circumstances, I would argue, such performances must be less an epistemological given than a leap of both hope and imagination.

Anne Whitehead's work suggests that such a dilemma of performance and definition is part and parcel of all work in the area of trauma narrative. As she states trauma emerges as that which, at the very moment of its reception, registers as a nonexperience, causing conventional epistemologies to falter' (5). Whitehead presents trauma fiction as a valuable and inevitable response to the failure of language to communicate the terrible knowledge gained through traumatic experience. For the victim of violence, Whitehead claims,

History is no longer available as a completed knowledge, but [...] perpetually escapes or eludes our understanding. Such a notion of history implicitly repositions the relation between language and the world so that the text shifts from a reflective mode [. . . ] to a performative art, in which the text becomes imbricated in our attempts to perceive and understand the world around us. (13)

\footnotetext{
${ }^{17}$ For a further discussion of these debates, see Gudmundsdottir, in J ensen and J ordan, eds., 2009,pp. 112-121 and more recently, Smith and Watson in McClennen and Schultheis Moore eds, 2015, pp. 243252.
} 
These performances of self-hood are of course enacted by all persons, not only those who have suffered violent trauma. For us, however, the self-narrative takes on a particular significance as we negotiate the competing desires for disclosure/performance (the need to tell one's story and be listened to) and silence (to deny and/or avoid reliving the experience). Leigh Gilmore asks 'can language be found for this experience? Will a listener emerge who can hear it?' (6). Her questions reminds us that navigating the complex waters of post-trauma identity narratives is no easy task. Indeed, for some writers, negotiating the truth becomes the work of a lifetime.

\section{1. 'Does the Whale's magnitude diminish? Will he perish?' (Moby Dick)}

In Virginia Woolf's late memoir, 'Sketch of the Past,' she recalls the 'small looking-glass in the hall at Talland House' in St I ves and the 'looking glass-shame' she continued to feel, and links this shame to being molested as a 'very small' child by her much older step-brother in that same hallway (40). As many scholars have noted, the images of the sea, of mirrors, and of unspoken shame that surface throughout Woolf's fiction, are compelling repetitive tropes whose meanings are elusive, fragmentary and contradictory. ${ }^{18}$ Like Kerouac, Melville and Ballard, Woolf's identity as writer, evidenced by her overwhelming productivity despite chronic bouts of debilitating illness, was a constructed self-narrative that drew on her traumatic experience but was not limited to it. Woolf's use of symbolic modes for negotiating the difficult truths of her past, moreover, may tell us something about the ultimate function and purpose of posttrauma identity narratives: in Ishmael's words, 'surely all this is not without meaning'.

One argument for understanding the importance of narrative identity is that they provide us with just such meaning. As psychotherapist Donald Polkinghorne has argued:

${ }^{18}$ Woolf's repeated use of these tropes is discussed in J ensen, 2012; Squiers, 1981; Bradshaw, 2009. 
Narrative is a scheme by means of which human beings give meaning to their experiences of temporality and personal action. [ . . . It is the primary means by which human existence is rendered meaningful. (11) Polkinghorne's explanation is vital to our understanding of the therapeutic value of selfnarratives, but is particularly interesting for clarifying the specific function of fictive, rather than literal forms, in post-traumatic narratives: for it must be only in the realm of imagination that meaning can be ascribed to acts of violent emotional or physical incursion. The pressure to find that meaning, moreover may force the teller to exceed the boundaries of factual documentation.

Because traumatic experience exists in the body as a perpetual 'now,' the usual reflective process of assigning meaning to experience through memory may be stalled at the first hurdle. Autobiographical fiction, by contrast, offers another, and perhaps more useful, form of reflection in the upside down epistemology of trauma, when the very nature of facts, figures, memories and meaning are in question. Metaphor, imagination and the symbolic are needed most where the significance of experience is least clear. ${ }^{19}$

\section{2. 'It is not down on any map; true places never are.' (Moby Dick)}

As Kate Douglas's work demonstrates, we all want to read tales of the triumph of the human spirit. So what becomes of the loss and anger felt by victims of violent trauma? For all the writers I have discussed here, including myself, these emotions came to percolate through the repetitive symbolism contained in their fiction and the new identity narratives forged in the act of writing. In an attempt to exorcise the difference inscribed by trauma, to transition from 'what I was' to 'what I may be' these writers swerved from the mirror to the easel and from fact to metaphor in an attempt to avoid drowning, like Narcissus, in their own insufficiently mediated reflections. The attempt, as even the briefest glance at a biography of Melville, Woolf and Kerouac suggests,

\footnotetext{
${ }^{19}$ This idea is explored in detail in Gilmore, 2001.
} 
might not have been entirely successful. We may believe that for them, the impulse for self-destruction was too great to overcome, even through writing. Likewise, the dark dystopian worlds of Ballard's late fiction hint at a life in which suffering is common and compassion rare. My own experience, however, enables me to read the events of these writers' lives somewhat differently.

To make this argument I offer a further excerpt from my novel, which, as I now understand, both exemplifies and challenges some of the ideas and concerns I have explored in this essay.

\section{From Saints in Staten Island}

\section{What did and didn't happen.}

\section{Here's what did happen to Bernadette:}

When she was 9 or 10 years old, she watched and did nothing while she saw someone she loved get beaten up and raped. She watched and did nothing when it happened to her as well. She hovered above herself, looking down, just like they say people do when they die-hang around over their bodies, watching, taking notes. Bernadette could see the statue of the lady beneath her while she flew, high above the park and harbor and Clinton Street. High above herself and free.

\section{Here's what didn't happen:}

Soon after this day at the park-Bernadette and the other girl did not go and tell their parents what happened. They did not go to the doctor or the police or get any kind of counseling. They did not assume that this was the fault of the boys that jumped them. They did not forget or forgive themselves for being where they should not have been. They did not grow up to be happy and well-adjusted individuals. They did not write best-selling memoirs and appear on the Oprah Winfrey show. They did not believe that they had not deserved it, that they had not asked for it. Bernadette did not develop and 
then conquer an eating disorder as a result of this experience. She is not a recovering alcoholic. She has not quit smoking. What happened is that the two little girls who were raped in the park where they should not have been did not get over it. Which is not a story people want to hear. (166-7)

What I see now in this passage is that writing about my experience did not enable me to 'get over it' in any simple way. Nothing could. There is no way in this world to change the past. But, for the most part, the future is mine to imagine.

And there's more. Melville, Woolf, Kerouac and Ballard stand among the greatest writers of the last two hundred years. Their works are revered and debated over, studied by academics and enjoyed by 'common readers.' By any measure they were successful in forging new public narrative identities far beyond their victimhood. Privately, however, their suffering no doubt continued. It haunts their characters from Bartelby to Clarissa Dalloway to Sal Paradise to Ballard's namesake J im, each of whom mourns a lost self, the person they would have become if only trauma had not struck.

As the novelist Kazuo I shiguro once said, fiction contains 'the comedy and pathos and the sorrow of the stories we tell ourselves to keep other stories away' (cited in Wood, 158). In this context, a factual account of 'what did and didn't happen' misses the point. Metaphoric and fictive forms allow victims of trauma the chance to confront, reinvent and revise the past. By doing so, we negotiate both truth and knowledge with 'the ungraspable phantom of life' and come to construct a new, socially acceptable narrative identity necessary to our survival. Surviving to tell the story, here, is the point. Bernadette may be stuck, still at the mercy of the boys in the park, but / am not. Or at least not always. I sit at my desk, tapping my keys. Safe. Downstairs my daughter plays piano and my husband makes dinner. Safe. And that, in I shmael's words is 'the key to it all.' 


\section{WORKS CITED}

Adorno, Theodor. Prisms. $6^{\text {th }}$ Ed. Trans. Samuel and Shierry Weber. Cambridge, Mass: MIT Press, 1967.

Ballard, J .G.'Look Back at Empire.' The Guardian. 4 March 2006. Web. 5 February 2011.

Bottalico, Barbara and Tommasso Bruni, 'Post-Traumatic Stress Disorder, Neuroscience and the Law' International Journal of Law and Psychiatry, 2012 (35): 112-20.

Bradshaw,David. "The Purest Ecstasy": Virginia Woolf and the Sea, in Modernism on Sea: Art and Culture at the British Seaside. Eds. Lara Fleigel and Alexander Harrison. Oxfordshire: Peter Lang Ltd, 2009,101116.

Carroll, Noel. 'Art, Narrative and Moral Understanding,' in J errold Levinson, Ed. Aesthetics and Ethics:

Essays at the Intersection. Cambridge: Cambridge University Press, 1998, 126-160, pp. 138-9.

Caruth, Cathy. Trauma: Explorations in Memory, Baltimore: J ohns Hopkins University Press, 1995.

Culbertson, Roberta. 'Embodied Memory, Transcendence, and Telling: Recounting Trauma, Reestablishing the Self. ' New Literary History, 1996. 26: 169-95.

Currie, Gregory. 'Realism of character and the Value of Fiction,' in Levinson (1998) 161-81.

Damasio, Antonio. The Feeling of What Happens: Body, Emotion, and the Making of Consciousness. London: Vintage, 2000.

Delbanco, Andrew. Melville His World and Work, New York: Alfred A. Knopf, 2005.

Parker, Hershel. Herman Me/ville: A Biography. Baltimore: J ohns Hopkins University Press, 2005.

Douglas, Kate. Contesting Childhood: Autobiography, Trauma and Memory. New Brunswick, New Jersey: Rutgers University Press, 2010.

Eakin, Paul J ohn. Living Autobiographically. Ithaca: Cornell UP, 2008.

Esterling, B. A., L'Abate, L., Murray, E. J., and Pennebaker, J. W. 'Empirical foundations for writing in prevention and psychotherapy: mental and physical health outcomes.' Clinical Psychology Review, 1999, (19): $79-96$.

Gilmore, Leigh. The Limits of Autobiography. Ithaca: Cornell University Press, 2001. Hunt, Celia, 'Therapeutic Effects of Writing Fictional Autobiography,' Life Writing 7, vol. 3 (2010): 231244.

Gudmundsdottir, Gunnthorunn. 'Fake Autobiography and Postmemory: The Aftermath of the Wilkomirski Scandal,' in Meg J ensen and J ane J ordan, eds. Life Writing: The State of the Art and The Spirit of the Age. Newcastle: Cambridge Scholars Press, 2009,pp. 112- 121.

Hunt, Celia. 'The Therapeutic Dimensions of Autobiography.' London: J essica Kingsley, 2000. 
-. Transformative Learning through Creative Life Writing: Exploring the self in the learning process. New York and London: Routledge, 2013.

International Protocol on the Documentation and Investigation of Sexual Violence in Conflict. J une 2014, First Edition. UK: Foreign and Commonwealth Office.

J ensen, Meg. 'The Legible Face of Human Rights in Autobiographically-Based Fiction.' Routledge Companion to Literature and Human Rights, London: Routledge, 2015,pp. 184-192.

-.. 'Post-Traumatic Memory Projects: Autobiographical Fiction and Counter-monuments' Textual Practice 28:4 (2014): 701-725.

-. Saints in Staten Island: A Novel (unpublished).

-. 'The Writer's Diary as Borderland: The Public and Private Selves of Virginia Woolf, Katherine Mansfield and Louisa May Alcott.' Life Writing, Special Issue: Writing Between Lives: Life Writing and the Work of Mediation. 9.3 (2012): 315-325.

Kerouac ${ }_{\downarrow}$ ack. Visions of Gerard. New York: Farrar, Strauss and Co, 1963.

LaCapra, Dominick. Representing the Holocaust. Ithaca: Cornell University Press, 1996.

Lejeune, Phillipe._On Autobiography. Trans. Katherine Leary. Ed. Paul J ohn Eakin. Minneapolis: University of Minnesota Press, 1989.

MacPherson, J ane. 'Does Narrative Exposure Therapy Reduce PTSD in Survivors of Mass Violence.' Research on Social Work Practice. 20102, 22 (1): 29-42.

Marcuse, Herbert. The Aesthetic Dimension. Boston: Beacon Press, 1977.

McLoughlin, Dominic. 'Transition, transformation and the art of losing: some uses of poetry in hospice care for the terminally ill.' Psychodynamic Counselling, 2000, 6 (2): 215-234.

Mitchell, J uliet. 'Trauma, Recognition and the Place of Language,' 'Trauma, Recognition and the Place of Language' Diacritics, 28:4 (Winter 1998): 121-33.

Melville, Herman. 'Bartleby the Scrivener' (1853). London: Hesperus Press, 2007.

---. 'Hawthorne and his Mosses,' (1850). London: The Perfect Library, 2014.

---. Moby Dick (1851). Ed. Peter Batke. The Text Archive. Princeton University, 1995. Web. 20 J uly 2011.

---. Redburn: His First Voyage (1849). London: British Library, 2010.

-. The Writings of Herman Melville, Vol. 4. Eds. H. Hayford, H. Parker, G.T. Tanselle. Evanston and Chicago: Northwestern University Press.

Nicholls, Sophie. 'Beyond Expressive Writing: Evolving Models of Developmental Creative Writing'. Journal of Health Psychology, 2009 14:171-180.

Payne, Martin. Narrative Therapy. $3^{\text {rd }}$ Ed. London: Sage, 2006.

Polkinghorne, David. Narrative Knowing and the Human Sciences. Albany: SUNY Press, 1988, 11. 
Pennebaker, J.W. and J.D. Seagall. 'Forming a story: the health benefits of narrative.' Journal of Clinical Psychology, 1999, 55 (10):1243-54.

Richardson, Michael. 'Writing Trauma: Affected in the Act', New Writing: The International Journal for the Practice and Theory of Creative Writing, 2013. 10 (2): 154-162.

Robjant, Katy and Mina Fazel, 'The emerging evidence for Narrative Exposure Therapy: A review.' Clinical Psychology Review 30 (2010): 1030-1039.

Rogin, Michael Paul. Subversive Genealogy: The Politics and Art of Herman Melville. Berkeley: University of California Press, 1992.

Sacks, Oliver. 'A Matter of Identity' in The Man Who Mistook his Wife for a Hat, London: Duckworth, 1985, pp. 103-110.

Schauer, Maggie, Frank Neuner, Thomas Elbert. Narrative Exposure Therapy : a short-term treatment for traumatic stress disorders. $2^{\text {nd }}$ rev. and expanded ed. Boston: Hogrefe Publishing, 2011.

Shneidman, Edwin. Autopsy of a Suicidal Mind, Oxford: Oxford University Press, 2004.

Smith, Sidonie and J ulia Watson. 'What about False Witnessing?' in McClennen and Schultheis Moore, eds. Routledge Companion to Literature and Human Rights, Routledge, 2015, pp. 243-252.

Squiers, Susan. 'Mirroring and Mothering: Reflections on the Mirror Encounter Metaphor in Virginia Woolf's Works.' Twentieth Century Literature, 27.3 (Autumn 1981):272-88.

Strawson Galen. 'Against Narrativity,' Ratio 17 (2004):428-52.

Strickgold, Robert. 'EMDR: A Putative Neurobiological Mechanism of Action' Journal of Clinical Psychology, 58:1 (2002): 61-75.

Tytell, J ohn. Naked Angels: Kerouac, Ginsberg, Burroughs. New York: Grove Press, 1976.

van der Kolk, Bessell. 'Dissociation and the fragmentary nature of traumatic memories: overview and exploratory study.' Journal of Traumatic Stress, 1995 8, (4): 505-25.

Whitebrook, Maureen. Identity, Narrative and Politics. London: Routledge, 2001.

Whitehead, Anne. Trauma Fiction. Edinburgh, Edinburgh University Press, 2004.

Winnicott, Dale. Playing and Reality. London: Tavistock, 1971.

Wood, Michael. Children of Silence: Studies in Contemporary Fiction, New York: Columbia University Press, 1999.

Woolf, Virginia. 'A Sketch of the Past,' in Moments of Being. Ed. J. Schulkind, $2^{\text {nd }}$ edition. London: Hogarth Press, 1985. 